\title{
Knowledge Attitude and Practice towards Visceral Leishmaniasis among Residents and Health Professionals in Welkait District, Western Tigray, Ethiopia
}

\author{
Mebrahtu Berhe ${ }^{1,2 *}$, Abrha Bsrat ${ }^{2}$, Habtamu Taddele ${ }^{2}$, Endalemaw Gadissa ${ }^{3}$, Yohannes Hagos ${ }^{2}$, Yohannes Tekle ${ }^{2}$ and Adugna Abera ${ }^{4}$ \\ ${ }^{1}$ Ethiopian Veterinary Drug and Animal Feed Administration and Control Authority, Tigray Regional Branch Coordination Office, Mekelle, Ethiopia \\ ${ }^{2}$ Mekelle University College of Veterinary Medicine, Mekelle, Ethiopia \\ ${ }^{3}$ Armauer Hansen Research Institute, Addis Ababa, Ethiopia \\ ${ }^{4}$ Ethiopian Public Health Institute, Addis Ababa, Ethiopia
}

*Corresponding author: Berhe M, Ethiopian Veterinary Drug and Animal Feed Administration and Control Authority, Tigray Regional Branch Coordination Office, Mekelle, Ethiopia, Tel: +81-980522719; E-mail: berhe.mebrahtu@yahoo.com

Received date: January 02, 2018; Accepted date: February 20, 2018; Published date: February 28, 2018

Copyright: $\odot 2018$ Berhe $\mathrm{M}$, et al. This is an open-access article distributed under the terms of the Creative Commons Attribution License, which permits unrestricted use, distribution, and reproduction in any medium, provided the original author and source are credited.

\begin{abstract}
Visceral Leishmaniasis is becoming a major public health problem both in terms of geographical spread and incidence in Ethiopia although failed to attract the attention it deserves. Magnitude,public health impact and dynamics of the disease in Ethiopia are not well studied. Hence,this study was conducted in Welkait district to determine public awareness about the disease. Wekait is a highly productive area having a conducive environment for the spread of the parasite. A cross sectional study was employed in purposively selected sub-districts in which house to house survey was carried out using a pre-tested semi-structured questionnaire. A total of 288 participants (264 household heads and 24 health professionals) were interviewed to assess their knowledge, attitude and practice towards visceral leishmaniasis. Overall score of the participants showed that $59 \%, 95 \%$ and $53 \%$ of them were knowledgeable have positive attitude and good practice on visceral leishmaniasis, respectively. Sex, educational status and history of travel profile showed significant association with the knowledge of participants. The study also revealed a gap in the knowledge and practices of health professionals about the disease. The present study highlighted an overall positive attitude regarding the disease. However, the gap in knowledge and poor practice calls for an intervention to improve the public awareness regarding visceral leishmaniasis in the study area.
\end{abstract}

Keywords: Attitude; Community; Knowledge; Health-professionals; Practice; Visceral-leishmaniasis

\section{Abbreviations:}

KAP: Knowledge, attitude and practice; VL: Visceral leishmaniasis

\section{Introduction}

Visceral leishmaniasis (VL), commonly known as kala-azar is a systemic disease caused by parasitic protozoan species of genus Leishmansia. Leishmaniasis is a major vector-borne disease which, globally accounts for an estimated 50,000 deaths per annum. The disease is endemic in the tropical and subtropical regions of 98 countries [1].

Geographical distribution of leishmaniasis depends on factors associated with economic development, such as widespread urbanization, deforestation and development of new settlements. Moreover, migration of peoples from rural to urban areas is also responsible for spreading pattern of the disease [2]

In Ethiopia, leishmaniasis is among the major vector-borne diseases with variable ecology and epidemiology. Ethiopia is one of the six WHO recognized countries, which these countries alone representing more than $90 \%$ of global burden of visceral leishmaniasis [1,3]. Dogs are considered as the reservoir hosts for $L$. donovani the causative agent of visceral leishmaniasis [4-6]. In countries like Ethiopia where there are dozens of free-roaming and stray dogs, the situation of VL transmission dynamics is expected to be worse. Following Sudan, Ethiopia has the second largest number of VL cases of any country in Sub-Saharan Africa (SSA) region, with an estimated 4000-7000 people needing treatment for the disease each year $[7,8]$.

The lowland areas of Northwestern Ethiopia where there is intensive migration of labor force,the incidence of the disease is very high and the endemic nature of the disease have been reported in Humera and Metema with an incidence of 1000-2000 human cases annually [8-10]. Visceral leishmaniasis is often found in areas that are remote, with absent or undeveloped health facilities, where tools for screening and identification of patients are inadequate,and above all with no or few trained man power. Due to lack of knowledge and updated information, even the most critical cases remain untreated or unreported, that tends to represent as a reservoir of the infection $[11,12]$.

Welkait district, the study site of the present investigation, is found in the North-west lowlands of Ethiopia and is expected to be endemic for VL. According to the hospital reports of the Welkait district health office, there was a visceral leishmaniasis (VL) outbreak in 2013 in a specific area called Korarit sub-district, making the disease a public health concern for the regional health authorities ever since. Since Welkait district is suitable for commercial agriculture and livestock development activities, it has been identified by the government for a mega sugar project. For this reason, residents of the surroundings have been re-settled in to another areas [13], that leading them to expose for 
Citation: Berhe M, Bsrat A, Taddele H, Gadissa E, Hagos Y, et al. (2018) Knowledge Attitude and Practice towards Visceral Leishmaniasis among Residents and Health Professionals in Welkait District, Western Tigray, Ethiopia. J Trop Dis 6: 257. doi:10.4172/2329-891X. 1000257

Page 2 of 8

a new inhabitants. This in turn brings new dynamism of increasing risk factors which include rapid urbanization, deforestation, new settlements, migration, cross-border movement to/from Humera, which is a VL endemic area that makes the disease a growing public health concern in the region [14].

Efforts are being made by the Ethiopian government and its partners in order to control and prevent the incidence of visceral leishmaniasis. In order for these control and prevention measures to be effective and successful the participation of the local community is of paramount importance. Unless there is cooperation and participation from the vulnerable and affected communities, the implementation of the control and preventive measures could be in question $[11,15]$. In order to be cooperative and participate in the control and prevention strategies,knowledge, attitude and practice (KAP) of the community towards the disease is major determinant factor. The prevalence of VL has being increased in different parts of Ethiopia due to different reasons like HIV co-infection, antimonial drug efficacy and others [16-21]. Several VL studies regarding community KAP have been undertaken in different parts of the world [15,22-25]. But, to the extent of the researchers knowledge, there are only two community KAP studies regarding VL conducted in South Gondar, Ethiopia [11]. Therefore, the present study was designed to assess VL related knowledge, attitude and practice of residents in Welkait district, an area expected to be endemic for VL in Northwest Ethiopia.

\section{Materials and Methods}

\section{Study area and population}

Welkait district is found in Western Tigray region, North-western Ethiopia, $437 \mathrm{~km}$ away from Mekelle,the capital city of Tigray National Regional State, and $1220 \mathrm{~km}$ away from Addis Ababa. Welkait is found between $13^{\circ} 30^{\prime} 00^{\prime \prime}$ and $14^{\circ} 07^{\prime} 00^{\prime \prime}$ North latitude and $36^{\circ} 40^{\prime} 15^{\prime \prime}$ and $37^{\circ} 48^{\prime} 00^{\prime \prime}$ East longitude with an altitude ranging from 677 to 2755 meter above sea level.

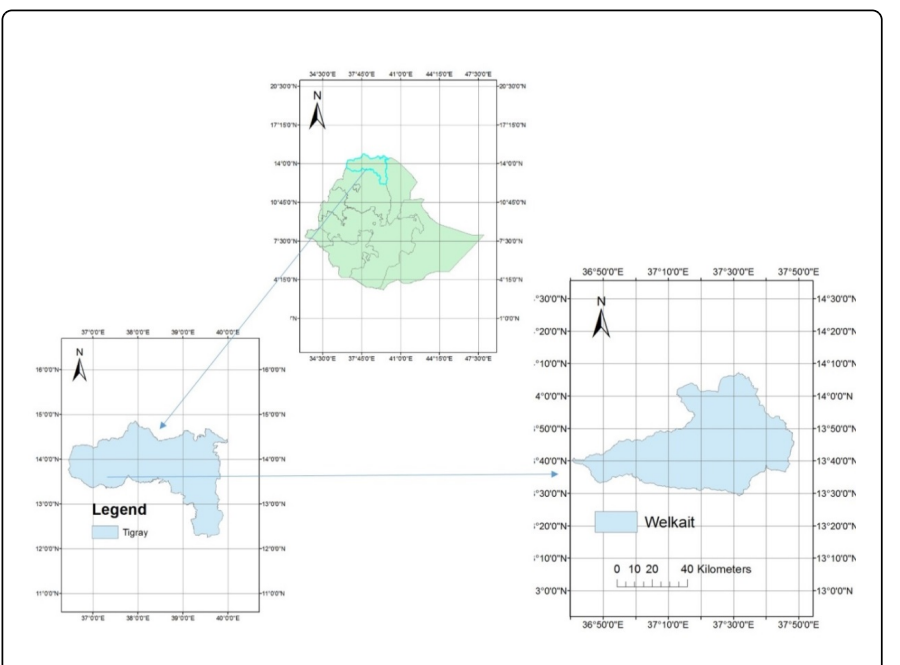

Figure 1: Map of the study district.

The district has 28 sub-districts of which 14 are with low land agroecology. Welkait is bordered by Tselemti, Tahtay Adiabo, Asgede Tsimbla, Kafta Humera and Tsegede districts in east, north, north eastern, north and north western, south and south western, respectively. The annual temperature and unimodal rainfall of the district are $17.5-25^{\circ} \mathrm{C}$ and $700-1800 \mathrm{~mm}$, respectively [26]. The total population of the district is 163,993 (83,129 male and 80,110 females) of which $85 \%(138,731)$ are rural settlers. A total of $35,215(\mathrm{M}=28,175$ and $\mathrm{F}=7,040$ ) household heads are found in the district [13] (Figure 1).

\section{Study design and sample size determination}

A cross-sectional study was conducted from November 2015 to June 2016 using a questionnaire based survey in Welkait district, Western Tigray, Ethiopia. The sample size for the questionnaire based survey was calculated using the statistical formula, $\mathrm{n}=\mathrm{N} / 1+\mathrm{N}[\mathrm{e}]^{2}$ where, $\mathrm{n}=$ number of study subjects (household heads) enrolled in the study, $\mathrm{N}=$ total population of the study districts, $\mathrm{e}=$ acceptable error for questionnaire based survey (6\%). Accordingly, the sample size was calculated to be 269 . However, to increase the precision, a total of 288 participants (264 household heads and 24 health professionals from three health centers) found in the six study sub-districts were considered for the questionnaire survey. In addition, a four year retrospective data on both clinically suspected and laboratory confirmed visceral leishmaniasis cases were obtained from the district health office. Similar study designs were also employed to assess the $\mathrm{KAP}$ of the community in VL vulnerable areas [11,15,22-23]

\section{Sampling technique}

A two stage sampling strategy was employed to collect the required data. Selection of sub-districts was conducted purposively based up on their previous history of exposure to VL in reference to the recorded data of Welkait-district health office annual reports, transport accessibility and geographical situation [27].

Accordingly, Wef-argif, Ksad-delesa, Adi-jamus, Korarit, Bet-mulu and Laelay-mayhumer sub-districts were purposively included in the present study. A complete household listing was then carried out in each selected sub-districts and a proportionate sample size allocation was done to each selected sub-districts. From each selected household a single participant (household head) who was voluntary and agreed to give informed consent was selected for interview. In some cases, where households were not being able to be accessed for any reason, the next house was chosen to be involved.

\section{Data collection}

A pre-tested semi-structured questionnaire was employed to obtain required information from selected household heads and health professionals with an interviewer administered face to face interview. Information about socio-demographic profile and knowledge, attitude and practice of the study participants towards visceral leishmaniasis were collected. The questionnaire survey had four different parts: the socio-demographic profile; knowledge; attitude and practice. The questionnaire survey had both open and close ended questions. Pretesting was done on 15 (5\%) individuals exclusively, earlier than the actual data collection period.

Categorization of socio-demographic characteristics were based on published references, age [28], family size [18], educational status [15] and occupation [29].

Scoring: This method was used based on the technique [11]. For knowledge,each correct response was given a score of 1 or 0 otherwise. Total knowledge scores can range between 0-8. Knowledge scores between 0 and 4 were considered as poor knowledge,while knowledge 
Citation: Berhe M, Bsrat A, Taddele H, Gadissa E, Hagos Y, et al. (2018) Knowledge Attitude and Practice towards Visceral Leishmaniasis among Residents and Health Professionals in Welkait District, Western Tigray, Ethiopia. J Trop Dis 6: 257. doi:10.4172/2329-891X. 1000257

Page 3 of 8

scores more than 4 were considered as good regarding VL. Attitude towards VL was assessed using a 6-item questionnaire: attitude scores between 0 and 3 was considered as negative, whereas scores more than 3 were considered as positive. Practice was also assessed using a 6-item questionnaire, and a score of more than 3 was considered as good practice for VL control.

\section{Retrospective data on VL}

A four year retrospective data on VL in the study district was collected from Welkait district health office. The data was disaggregated by suspected VL cases based on the working case definition at the health centers or health posts (adopted from the country case definition for VL) and confirmed VL cases if the cases were confirmed and reported as feedback from the neighboring districts with hospitals having VL diagnostic center, Kahsay Abera Hospital at Humera and Shire Endasillasie Hospital at Shire.

\section{Data management and analysis}

During data collection process, the data were checked for completeness and all incomplete or misfiled questions were sent back for correction. Data were double entered and analyzed using Stata version 12.1 [30]. Descriptive statistics were used to give a clear picture of background variables like age, sex and other variables in a semistructured questionnaire. Moreover, association of socio-demographic variables with the knowledge of individuals on VL was established considering a significance level of 0.05 ( $\mathrm{p}$-value $<0.05$ ). The frequency distribution of both dependent and independent variables were worked out. In addition, the retrospective data collected from the health office was analyzed using descriptive statistics and graphics.

\section{Ethical consideration}

Ethical approval to conduct the study was obtained from the Research Ethics Committee of the Tigray Science and Technology
Agency, represented by Mekelle University College of Health Sciences. Letter of permission to carry out the proposed research was obtained from the Tigray regional health bureau and respective district authorities. We considered oral consent in our study as majority of the participants were not being able to read and/or write. Participants were informed that, all the information they provided will be confidential. Besides, communication was made with their own local languages (Tigrigna/Amharic).

\section{Results}

\section{Socio-demographic profile of household heads}

Out of 264 interviewed household heads, 202 (76.52\%) were males and $62(23.48 \%)$ were females. The mean age of the participants was 40.29 (range, 18 to 80 ) and majority $220(83.33 \%$ ) of the participants were farmers. Regarding the education status of the participants,more than half of them 139 (52.65\%) was not able to read and write and 43 (16.29\%) participants were able to read and write through informal education. Majority of the participants, $212(80.3 \%)$ have lived more than three years in the study area and $74(28.03 \%)$ of the participants had an experience of travel to the VL endemic areas like Metema and Humera.

According to the present finding, socio-demographic characteristics such as sex,educational status and history of travel to VL endemic areas showed a statistically significant association ( $p$-value $<0.05)$ with the individual's knowledge on VL, where females (66\%), can't able to read and write $(50 \%)$ and those whom don't traveled to VL endemic areas $(51 \%)$ shown a poor knowledge score compared with their counterparts (Table 1).

\begin{tabular}{|c|c|c|c|c|}
\hline \multirow{2}{*}{$\begin{array}{l}\text { Characteristics } \\
\text { with their Categories }\end{array}$} & \multirow{2}{*}{$\begin{array}{l}\text { Total assessed } \\
\text { Frequency (\%) }\end{array}$} & \multicolumn{2}{|c|}{ Over all Knowledge } & \multirow{3}{*}{$\begin{array}{l}\text { P-value } \\
0.000\end{array}$} \\
\hline & & Poor (\%) & Good (\%) & \\
\hline Sex: Male & $202(76.52)$ & $68(33.66)$ & $134(66.34)$ & \\
\hline Female & $62(23.48)$ & $41(66.13)$ & $21(33.87)$ & \\
\hline Age: $18-40$ & $140(53.03)$ & $54(38.57)$ & $86(61.43)$ & 0.461 \\
\hline $41-63$ & $113(42.80)$ & $41(36.28)$ & $72(63.72)$ & \\
\hline$>64$ & $11(04.17)$ & $5(45.45)$ & $06(54.55)$ & \\
\hline Occupation: Farmer & $220(83.33)$ & $93(42.27)$ & $127(57.73)$ & 0.151 \\
\hline Student & $9(3.41)$ & $6(66.67)$ & $3(33.33)$ & \\
\hline Employee & $21(7.95)$ & $5(23.81)$ & $16(76.19)$ & \\
\hline Daily Laborer & $14(5.30)$ & $5(35.71)$ & $9(64.29)$ & \\
\hline Educational status: Illiterate & $139(52.65)$ & $70(50.36)$ & $69(49.64)$ & 0.004 \\
\hline Can read and write & $43(16.29)$ & $14(32.56)$ & $29(67.44)$ & \\
\hline Primary and secondary school & $69(26.14)$ & $24(34.78)$ & $45(65.22)$ & \\
\hline
\end{tabular}


Citation: Berhe M, Bsrat A, Taddele H, Gadissa E, Hagos Y, et al. (2018) Knowledge Attitude and Practice towards Visceral Leishmaniasis among Residents and Health Professionals in Welkait District, Western Tigray, Ethiopia. J Trop Dis 6: 257. doi:10.4172/2329-891X. 1000257

Page 4 of 8

\begin{tabular}{|l|l|l|l|}
\hline College and above & $13(4.92)$ & $1(7.69)$ & $12(92.31)$ \\
\hline Residence duration: <1 year & $20(7.58)$ & $7(35.00)$ & $13(65.00)$ \\
\hline $1-3$ years & $32(12.12)$ & $12(37.50)$ & $20(62.50)$ \\
\hline$>3$ years & $212(80.3)$ & $71(33.49)$ & $141(66.51)$ \\
\hline $\begin{array}{l}\text { Previous Travel to: Yes } \\
\text { No }\end{array}$ & $\begin{array}{l}74(28.03) \\
190(71.97)\end{array}$ & $\begin{array}{l}25(33.78) \\
97(51.05)\end{array}$ & $\begin{array}{l}49(66.22) \\
93(48.95)\end{array}$ \\
\hline
\end{tabular}

Table 1: Association among socio-demographic characteristics of residents' and their overall knowledge towards VL.

Association among socio-demographic characteristics of residents' and their overall knowledge towards VL was determined by cross tabulating each socio-demographic characteristic with the overall knowledge score. 5\% level of significance was considered and each character was evaluated to indicate its association for the presence of poor knowledge.

\section{Socio-demographic profile of health professionals}

A total of 24 (17 male, 7 female) health professionals working in different health centers and health posts of the study area were interviewed to assess their knowledge, perception and activities regarding VL. The mean age of the participants was 26.75 years (ranging from 21 to 38 years). Among those health professionals 13 $(54.17 \%)$ were nurses. Both residence duration and work experience of these professionals in the district were in a range of 1 to 10 years.

\section{Knowledge on VL among household heads}

All of the participants $264(100 \%)$ have previously heard about VL through different means. Almost half 128 (48.48\%) of the respondents have been able to be informed about VL through informal way (from neighborhoods, family members or friends). But, the remaining 56 (21.21\%), $44(16.66 \%)$ and $36(13.65 \%)$ had the chance of getting awareness about the disease from health services, school and public media (mainly television), respectively. Majority, 231 (87.5\%), of the respondents knew at least one clinical sign of $\mathrm{VL}$ and abdominal swelling was the most popularly known clinical sign, $141(61.04 \%)$. About 92 (34.85\%) of the respondents don't know the actual means of VL transmission and $38(41.3 \%)$ of them suggested that VL could be transmitted by drinking/bathing in dirty water bodies. About 81 (47.1\%) of the respondents are able to identify the sand fly from other flies, among which $67(82.72 \%)$ of them knew at least one resting/ breeding habitats of the sand fly. However, majority 235 (89.02\%) of the respondents were not aware of the zoonotic importance of VL. About 196 (74.24\%) of the study participants were aware of at least one preventive measure. Besides, majority 239 (90.53\%) of the respondents knew VL as being a treatable disease (Table 2).

\begin{tabular}{|c|c|c|c|}
\hline Assessments of Knowledge towards VL & Description & Frequency & Percentage \\
\hline \multirow[t]{2}{*}{ Previously aware of $\mathrm{VL}$} & Yes & 264 & 100 \\
\hline & No & 0 & 0.00 \\
\hline \multirow[t]{2}{*}{ Knowledge related with clinical signs } & Yes & 231 & 87.50 \\
\hline & No & 33 & 12.50 \\
\hline \multirow{2}{*}{ Knowledge about means of transmission } & Yes & 172 & 65.15 \\
\hline & No & 92 & 34.85 \\
\hline \multirow[t]{2}{*}{ Able to distinguish Sand fly, from other flies } & Yes & 81 & 30.68 \\
\hline & No & 183 & 69.32 \\
\hline \multirow[t]{2}{*}{ Knowing the breeding Sites of Sand fly } & Yes & 67 & 25.38 \\
\hline & No & 197 & 74.62 \\
\hline \multirow[t]{2}{*}{ Aware of the Zoonotic importance of VL } & Yes & 29 & 10.98 \\
\hline & No & 235 & 89.02 \\
\hline \multirow[t]{2}{*}{ Aware of any preventive measures for $\mathrm{VL}$} & Yes & 196 & 74.24 \\
\hline & No & 98 & 25.76 \\
\hline
\end{tabular}


Citation: Berhe M, Bsrat A, Taddele H, Gadissa E, Hagos Y, et al. (2018) Knowledge Attitude and Practice towards Visceral Leishmaniasis among Residents and Health Professionals in Welkait District, Western Tigray, Ethiopia. J Trop Dis 6: 257. doi:10.4172/2329-891X. 1000257

Page 5 of 8

\begin{tabular}{|c|c|c|c|}
\hline Knowing as, $V L$ is a treatable disease & Yes & 239 & 90.53 \\
\hline & No & 25 & 9.47 \\
\hline Over all knowledge & Good & 155 & 58.71 \\
\hline & Poor & 109 & 41.29 \\
\hline
\end{tabular}

Table 2: Residents knowledge towards VL in Welkait district, Western Tigray, Northwest Ethiopia, 2016.

Resident's knowledge towards Visceral Leishmaniasis was assessed on participants whom previously have heard about the disease. More than one answer is possible for all of these questions provided.

\section{Health professionals knowledge on VL}

Despite, $15(62.5 \%)$ of the health professionals knew the anthroponotic modes of transmission regarding VL, only 9 (37.5\%) of them were being able to be aware of both anthroponotic and zoonotic means of transmission. However, 17 (70.83\%) of the health professionals were capable of distinguishing the sand fly, surprisingly only $6(25 \%)$ of them were aware that dogs are the major reservoir hosts for VL.

\section{Attitude of household heads towards VL}

Among all respondents 222 (84.09\%) of them agreed that VL was a major problem in their residence area,and 205 (77.65\%) respondents believed that they could possibly have the chance to get the disease. Among those respondents who believe that they couldn't get the disease,some of them think that they are protected from sand fly bite while others believe that they are not exposed to sand fly risk area.

\begin{tabular}{|c|c|c|c|}
\hline Assessments of Attitude & Description & Frequency & Percentage \\
\hline \multirow[t]{2}{*}{ Perceiving that, $\mathrm{VL}$ is a major problem in the area } & Yes & 222 & 84.09 \\
\hline & No & 42 & 15.91 \\
\hline \multirow[t]{2}{*}{ Believing that, he/she can gate VL } & Yes & 205 & 77.65 \\
\hline & No & 59 & 22.35 \\
\hline \multirow[t]{2}{*}{$\mathrm{VL}$ is a curable disease } & Yes & 233 & 88.26 \\
\hline & No & 31 & 11.74 \\
\hline \multirow[t]{2}{*}{ VL will be fatal, if it is left untreated } & Yes & 256 & 96.97 \\
\hline & No & 8 & 3.03 \\
\hline \multirow{2}{*}{ Community participation is crucial for VL control } & Yes & 193 & 73.11 \\
\hline & No & 71 & 26.89 \\
\hline \multirow[t]{2}{*}{ Prioritizing health service in case of $V L$ treatment } & Yes & 257 & 97.35 \\
\hline & No & 7 & 2.65 \\
\hline \multirow[t]{2}{*}{ Over all Attitude } & Positive & 250 & 94.69 \\
\hline & Negative & 14 & 5.31 \\
\hline
\end{tabular}

Table 3: Attitude towards VL among household heads in Welkait district, Western Tigray, Northwest Ethiopia, 2016.

Majority of participants believe that VL is a curable disease 233 (88.26\%) and about $193(73.11 \%)$ respondents indicated that community participation is an essential tool to control VL. However,the minority indicated that only the government could have the potential to control VL. Among the study participants, about $97.35 \%(257 / 264)$ of them go to health service as their first priority for VL treatment but,the remaining 7 (2.65\%) respondents prefer traditional medication due to the reason that,they had a better experience earlier and being confident on the practitioners (Table 3 ).

The attitude of household heads towards VL in the study area was assessed, focusing on individual's perception related with the nature, epidemics and possibilities to manage the disease. Those Respondents who said yes for some questions (possible to be infected, need of community participation and treatment preference area) were further asked to explain their reason.

\section{Attitude of health professionals towards VL}

Majority of the health professionals 22 (91.7\%) reported as VL is a major health problem in their working area. Moreover, they believed that the available health professionals are not sufficient 17 (70.83\%) and well trained $16(66.7 \%)$ to provide health services for VL patients. 
Citation: Berhe M, Bsrat A, Taddele H, Gadissa E, Hagos Y, et al. (2018) Knowledge Attitude and Practice towards Visceral Leishmaniasis among Residents and Health Professionals in Welkait District, Western Tigray, Ethiopia. J Trop Dis 6: 257. doi:10.4172/2329-891X. 1000257

Page 6 of 8

\section{Residents practice towards VL prevention and control}

In relation to VL prevention and control activities performed in the study area, majority 249 (94.50\%) of the respondents declared that, they had never ever applied insecticide spray in to their house/ surrounding area,and those who applied insecticides, they do it privately during the rainy season just on the mosquito breeding sites around their compound. Among respondents more than half, 166 $(62.88 \%)$, had an experience of outdoor sleeping specially during high temperature, but, almost half of the participants (44.32\%) slept near animals, to keep them from thief. Moreover, 203 (76.89\%) of the respondents have had at least one bed net in their family. Among the participants with insufficient bed net $98(88.29 \%)$ give priority to children and women to sleep under the available bed nets. Among the VL preventive measures exercised in the study area, 88 (33.33\%) and $163(61.74 \%)$ respondents use repellents and chopped plant parts to protect themselves from any biting flies, respectively. The most commonly used repellent was the BUZZ-OFF Anti-Mosquito Repellent,and that of the smocking plants were, locally named as AKUMA and AWllie (Table 4).

\begin{tabular}{|c|c|c|c|}
\hline Assessments of Practice & Description & Frequency & Percentage \\
\hline \multirow[t]{2}{*}{ Spraying the house/compound with insecticides } & Yes & 15 & 5.5 \\
\hline & No & 249 & 94.50 \\
\hline \multirow[t]{2}{*}{ Sleeping outside (outdoor) } & Yes & 166 & 62.88 \\
\hline & No & 98 & 37.12 \\
\hline \multirow[t]{2}{*}{ Sleeping near animals } & Yes & 117 & 44.32 \\
\hline & No & 147 & 55.68 \\
\hline \multirow[t]{2}{*}{ Owning a bed net at family level } & Yes & 203 & 76.89 \\
\hline & No & 61 & 23.11 \\
\hline \multirow[t]{2}{*}{ Repellent Usage against baiting flies } & Yes & 88 & 33.33 \\
\hline & No & 176 & 66.67 \\
\hline \multirow[t]{2}{*}{ Using smoke/fumigate against biting flies } & Yes & 163 & 61.74 \\
\hline & No & 101 & 38.26 \\
\hline \multirow[t]{2}{*}{ Over all practice } & Good & 141 & 53.41 \\
\hline & Poor & 124 & 46.59 \\
\hline
\end{tabular}

Table 4: Residents practice towards VL prevention and control in Welkait district, Western Tigray, Northwest Ethiopia, 2016.

Residents practices related with prevention and control of VL was assessed with respect to behavioral, environmental, cultural and other perspectives. Respondents, whatever (bad or good) practice they had been performing were further asked to explain about it.

\section{Health professionals practice regarding VL prevention and control}

All of the participated health professionals (100\%) reported that, clinical diagnosis and public education were the only VL related health services and absence of diagnostic and treatment facility were the major problems that limit them to deliver an optimal service to patients suffering form VL.

\section{Retrospective data on VL}

The retrospective data for visceral leishmaniasis showed 20 clinically suspected and 12 laboratory confirmed cases from the period of 2012 to 2015 (Table 5).

Four years retrospective data of clinically suspected and laboratory confirmed cases of Visceral Leishmaniasis in the study area were simply described by counting the number of patients on each respected years. Health centers in the sub-districts record VL suspected cases that came to their health centers. The laboratory confirmed cases indicated were only feedbacks reported from Shire Hospital and Kahsay Abera Hospital (near bye areas outside the district).

\begin{tabular}{|c|c|c|c|c|c|}
\hline \multirow[t]{3}{*}{ Years } & \multicolumn{4}{|c|}{ Clinically Suspected VL Cases } & \multirow{3}{*}{$\begin{array}{l}\text { Laboratory } \\
\text { Confirmed } \\
\text { VL Cases }\end{array}$} \\
\hline & \multicolumn{2}{|c|}{ Sex } & \multicolumn{2}{|c|}{ Age } & \\
\hline & Male & Female & 5 to 15 year & $>15$ year & \\
\hline 2005 & 6 & 0 & 2 & 4 & 1 \\
\hline 2006 & 5 & 1 & 1 & 5 & 6 \\
\hline 2007 & 2 & 1 & 0 & 2 & 2 \\
\hline 2008 & 4 & 1 & 1 & 4 & 3 \\
\hline
\end{tabular}

Table 5: Retrospective data of clinically suspected and laboratory confirmed cases of visceral leishmaniasis. 


\section{Discussion}

Visceral leishmaniasis is one of the major vector-borne protozoan parasites that impedes both economic and public health significance in Ethiopia $[8,11,19]$. The findings of the present study indicated that male participants and those that had an experience of travel to VL endemic areas had a better knowledge about VL. A similar finding was reported from Adiss-zemen town in Northwestern Ethiopia [11]. This may be due to the reason that males have more experience of travel to different areas which could possibly meet peoples with different level of VL awareness. Educational status was also find to have a statistical significant association with VL knowledge of the participants which is consistent with that of de Amorim, Amóra [31] finding from Northeastern Brazil, which shows a significant association of educational status with that of participant's knowledge on VL transmission. This could be associated with the individual's access to better information regarding VL from different sources (public and social media,awareness raising activities in schools).

The finding of the present study indicated that all the interviewed participants had heard of the disease kal-azar (VL) but, only 155 (58.71\%) of them were knowledgeable which is in agreement with the previous reports [32]. However, a study [11], indicated a better knowledge of the study participants on VL. Most (88\%) of the respondents knew at least one clinical sign and symptom of VL. More than half of the respondents $(65.15 \%)$ were aware of the mode of transmission of the disease. The present finding was in close agreement with the result reported from rural communities of Amhara region, North-west Ethiopia [33], who reported that about $85 \%$ of the respondents were aware of at least one VL clinical sign and 59\% of them were aware of VL transmission through a biting fly. Moreover, a similar report was made by Alemu, Alemu [11] in Adis-zemen, Northwest Ethiopia where $82.5 \%$ of the respondents were aware of at least one clinical sign and about $68 \%$ knew that the disease is transmitted by sand flies. However, the present finding is higher than [15], whom reports from rural areas of India where $32 \%$ of the respondents were aware of any clinical sign and only $4 \%$ of them were aware that, VL is transmitted by sand flies. Such variability of knowledge among the various studies could be associated with the difference in the timing of the study, setting of the study and public awareness activities conducted in the areas.

Majority (89\%) of the household head respondents and $63 \%$ of the health professionals don't have information regarding the zoonotic importance of VL which could be associated with the lack of public educational interventions and health professional training on the area of zoonosis. Majority (91\%) of the study participants were aware of the curable nature of VL and similar results have been reported [34], from the rural areas of Gedarif state, Sudan.

According to the present study majority of the study participants have shown positive attitude towards VL (understand the fatality of the disease if untreated, prefer to visit health facilities, understand community involvement in the control and prevention of the disease). Even though there is a difference in the extent of understanding, comparable findings have been reported by other researchers in Ethiopia and other parts $[11,15,33]$. Moreover, the health professionals in the study districts were convinced that VL was one of the major health problems of the community. It has been indicated that for control and prevention measures to be effective, the involvement and cooperation of the community is of paramount importance $[11,15]$.
In the present study it was evidenced that beyond a bed-net, other preventive and control activities were performed by the study participants to protect themselves from any kind of biting flies. Thus, $33 \%$ of respondents had an experience of using repellent, while $61 \%$ of them had the experience of using plant smoking/fumigation to protect themselves from biting fly. This may be due to the awareness creation and sensitization activities performed in relation to malaria control, the availability of anti-mosquito repellants in most drug shops and culture of the community to use plant parts for different smoking activities. Surprisingly, this study also found that $95.5 \%$ of the respondents had never experienced insecticide spray to their house/ compound. This finding is lower than the result from India which indicated $17 \%$ of respondents had performed an insecticide spray activities [15]. This could be associated with the awareness and accessibility of insecticides in the rural areas.

The retrospective data collected from the present study indicated a total of 20 and 12 clinically suspected and laboratory confirmed cases of visceral leishmaniasis respectively. It is expected that the actual incidence of the disease is higher than the reported cases and this could probably be under reporting of cases since the disease is neglected. However, several studies indicated for the higher prevalence of the disease in the neighboring areas like Kafta-Humera, Metema, Adiss-Zemen and Gondar both in humans and animals [5,16,28,32].

\section{Conclusion}

This current study had come up with interesting findings. However, it has been confirmed that,all of the respondents were being previously aware of VL. Serious knowledge gaps were exist both at community and health professional's level. Knowledge gaps mainly related with zoonotic nature of the disease, mode transmission and the sand-fly, which indicates for the existence of gaps in public education and communication efforts of the public health system. Residents of the study area have perceived well regarding the nature of the disease and they were also positive to play their role on its control if any call comes, which is a golden opportunity for any concerned body to intervene. Preventive measures related with self-protection against biting flies have been customized well although, activities like insecticide spray on surroundings was poorly practiced. This study has also indicated that, practically health centers of the study area were under reporting the disease. Therefore based on the conclusion we recommend the following recommendations.

Community education and continuous professional developments with special focus on females, individuals these can't able to read and write and also these whom didn't travelled to VL endemic areas are crucial, for the successful implementation of VL prevention and control strategies in the study area.

The an overall positive attitude of the residents towards the disease and their strong believe on the need of community participation for VL control is an essential ground that should have to be considered for implementing the intervention measures.

Although, individual's self-protection against biting fly is well practiced, the use of insecticide spray on house/surroundings is poorly practiced and the presence of bad sleeping habits among the community make things even worst. Hence, insecticide spray campaigns should have to be implemented.

The currently available reporting system of Visceral Leishmaniasis in the study area is poor, each health centers of the district and nearby 
Citation: Berhe M, Bsrat A, Taddele H, Gadissa E, Hagos Y, et al. (2018) Knowledge Attitude and Practice towards Visceral Leishmaniasis among Residents and Health Professionals in Welkait District, Western Tigray, Ethiopia. J Trop Dis 6: 257. doi:10.4172/2329-891X. 1000257

Page 8 of 8

hospitals undertaking VL diagnosis should have to improve their integration on feedback exchanging system. Beside, equipping health centers of the study area with diagnostic tools is mandatory.

Further researches should have to focus on the locally used smoking plants (local name: Akuma and Awllie) against biting fly, their impact mechanism.

\section{Acknowledgements}

The authors would to acknowledge Tigray Regional Health Bureau, Welkait District Health Office and the Sub-district Health Centers for their cooperation during the study time. Community of the district in general and study units in particular are highly acknowledged for their voluntary participation in the study.

\section{References}

1. WHO (2015) Investing to overcome the global impact of neglected tropical diseases: Third WHO report on neglected tropical diseases. WHO, Geneva.

2. Thakur C, Kanyok T, Pandey A, Sinha G, Zaniewski A, et al. (2000) A prospective randomized, comparative, open-label trial of the safety and efficacy of paromomycin (aminosidine) plus sodium stibogluconate versus sodium stibogluconate alone for the treatment of visceral leishmaniasis. Trans R Soc Trop Med Hyg 94: 429-431.

3. Abrha B, Nega B, Meshesha B, Mekonnen Y, Tsigemariam T, et al. (2015) Epidemiological study of cutaneous leishmaniasis in Saesie Tsaeda-Emba District, Eastern Tigray, Northern Ethiopia. Parasites and Vectors 8: 149.

4. Dantas TF (2007) Role of dogs as reservoirs of leishmania parasites, with emphasis on leishmania (leishmania) infantum and leishmania (viannia) braziliensis. Vet Parasitol 149: 139-146.

5. Kalayou S, Tadelle H, Bsrat A, Abebe N, Haileselassie M, et al. (2011) Serological evidence of Leishmania Donovani infection in apparently healthy dogs using direct agglutination test (dat) and rk39 dipstick tests in kafta humera, North West Ethiopia. Transbound Emerg Dis 58: 255-262.

6. Costa KFDL, Amóra SSA, Couto CFDA, Souza CDSFD, Silva LF, et al. (2014) Awareness of visceral leishmaniasis and its relationship to canine infection in riverside endemic areas in north-eastern brazil. Rev Soc Bras Med Trop 47: 607-612.

7. Hailu A, Dagne D, Boelaert M (2016) Leishmaniasis: Neglected tropical diseases Sub-Saharan Africa. Springer, New York. pp: 87-112.

8. Hailu A, Kroon C, Schoone G, Berhe N, Schallig H, et al. (2002) Seroepidemiological assessment and diagnosis of visceral leishmaniasis in an endemic locality using fast agglutination screening test (Fast). Acta Trop 83: 93-101.

9. Ritmeijer K, Veeken H, Melaku Y, Leal G, Amsalu R, et al. (2001) Ethiopian visceral leishmaniasis: generic and proprietary sodium stibogluconate are equivalent; HIV co-infected patients have a poor outcome. Trans R Soc Trop Med Hyg 95: 668-672.

10. Ritmeijer K, Dejenie A, Assefa Y, Hundie TB, Mesure J, et al. (2006) Comparison of miltefosine and sodium stibogluconate for treatment of visceral leishmaniasis in an ethiopian population with high prevalence of HIV infection. Clin Infect Dis 43: 357-364.

11. Alemu A, Alemu A, Esmael N, Dessie Y, Hamdu K, et al. (2013) Knowledge, attitude and practices related to visceral leishmaniasis among residents in Addis Zemen Town, South Gondar, and Northwest Ethiopia. BMC Public Health 13: 1.

12. Seleshi K (2007) Visceral leishmaniasis in Bira Abo, A Kebele in Addis Zemen, Sero-epidemological and skin test survey. Addis Ababa University, Addis Ababa.

13. CSA (2013) Population projection of ethiopia for all regions at woreda level from 2014-2017. Central Statistics Agency, Addis Ababa, Ethiopia.
14. Desjeux P (2001) The increase in risk factors for leishmaniasis worldwide. Trans R Soc Trop Med Hyg 95: 239-243.

15. Siddiqui N, Kumar N, Ranjan A, Pandey K, Das V, et al. (2010) Awareness about Kala-Azar disease and related preventive attitudes and practices in a highly endemic rural area of India. Southeast Asian J Trop Med Public Health 41: 1 .

16. Daniel A, Abate M, Merce H, Nohelly N, Tsegemariam, et al. (2013) Risk factors for visceral leishmaniasis among residents and migrants in KaftaHumera, Ethiopia. Plos Negl Trop Dis 7: 2543.

17. Samson L, Thi HTD, Frehiwot M, Gezahegn A (2014) Visceral leishmaniasis in Ethiopia: An evolving disease. Plos Negl Trop Dis 8: 3131.

18. Yared S, Deribe K, Gebreselassie A, Lemma W, Akililu E, et al. (2014) Risk factors of visceral leishmaniasis: A case control study in northwestern Ethiopia. Parasites \& Vectors 7: 470.

19. Suzi L, Hans V, Jean L (2003) Visceral leishmaniasis and HIV in Tigray, Ethiopia. Trop Med Int Health 8: 733-739.

20. Chance ML (1995) New development in the chemo-therapy of leishmanisis. Ann Trop Med Parasitol 89: 39-43.

21. Sulahian A, Garin YJ, Paratlong F, Dedet JP (1997) Experimental pathogenicity of viserotropic and dermotropic isolates of leishmania infantem from immuno compromized and immuno compitant patients in a muirine model. Fems Immunol Med Microbiol 17: 131-138.

22. Koirala S, Parija S, Karki P, Das M (1998) Knowledge, attitudes and practices about kala-azar and its sandfly vector in rural communities of Nepal. Bull World Health Organ 76: 485.

23. Singh SP, Reddy DC, Mishra RN, Sundar S (2006) Knowledge, attitude and practices related to kala-azar in a rural area of Bihar State, India. Am J Trop Med Hyg 75: 505-508.

24. Mondal D, Singh SP, Kumar N, Joshi A, Sundar S, et al. (2009) Visceral leishmaniasis elimination programme in India, Bangladesh and Nepal: Reshaping the case finding/case management strategy. Plos Negl Trop Dis 3: 355 .

25. Ahluwalia Ib, Bern C, Costa C, Akter T, Chowdhury R, et al. (2003) Visceral leishmaniasis: Consequences of a neglected disease in a Bangladeshi community. Am J Trop Med Hyg 69: 624-628.

26. OPFWD (2015) Annual statistical data of Welkait district. Office of Plan And Finance Welkait District, Welkait.

27. WDHO (2015) Welkait district annual health report. Welkait District Health Office, Welkait, Tigray, Ethiopia.

28. Wondimeneh Y, Takele Y, Atnafu A, Ferede G, Muluye D (2014) Trend analysis of visceral leishmaniasis at Addis Zemen Health Center, Northwest Ethiopia. Bio Med Research International.

29. Bantie K, Tessema F, Massa D, Tafere Y (2014) Factors associated with visceral leishmaniasis infection in North gondar zone, Amhara region, North west Ethiopia, case control study. Sci J Pub Heal 2: 560-568.

30. Stata (2011) Statacorp L. Stata Version 12.0. College Station. Tx: Statacorp Lp.

31. Amorim CF, Amóra SSA, Kazimoto TA, Costa KF, Silva LF, et al. (2015) Knowledge of the population about visceral leishmaniasis transmission in endemic areas near the banks of the Mossoró river in North-eastern Brazil. Int J Environ Res Public Health 12: 3343-3357.

32. Terefe Y, Afera B, Bsrat A, Syoum Z (2015) Distribution of human leishmaniasis and its associated risk factors in Metemma, Ethiopia. Epidemiology Research International 5.

33. López PN, Sordo L, Gadisa E, Cruz I, Hailu T, et al. (2014) Knowledge, attitudes and practices related to visceral leishmaniasis in rural communities of Amhara state: A longitudinal study in Northwest Ethiopia. Plos Negl Trop Dis 8: 2799.

34. Hassan MM, Banaga AO, Frah EA, Nour BY (2012) Assessment of knowledge, attitude and practice about sandfly and visceral leishmaniasis control activities in rural area of Gedarif state, Sudan. 